\title{
La aviación en Buenos Aires y el fenómeno noticioso global (1908-1910)
}

\author{
Pablo Ortemberg
}

Universidad Nacional de San Martín / CONICET

Aeronautas y aviadores ocupan todos los días algunas columnas en revistas y diarios.

Caras y Caretas, Buenos Aires,

$7 / 11 / 1908$

\section{El cable y el aeroplano: \\ una mise en page de la velocidad}

En 1920, el periódico argentino La Nación celebró su cincuentenario con un suplemento auto-dedicado. Presenta allí una sección con semblanzas de sus ilustres colaboradores "de hoy y de ayer"; y otra con el título "los corresponsales y colaboradores del exterior". Esta última contiene, a su vez, las rúbricas de "los corresponsales diarios de las grandes capitales", "una gran cantidad de publicistas de todo el mundo", y no se ahorran fotos de sus agencias en Londres, París y de las oficinas en Nueva York, Chicago y Boston. En España, además de haber creado su propia oficina de verano en San Sebastián, a cargo de su redactor-corresponsal Fernando Ortiz Echagüe, el periódico se enorgullece de su contrato especial con la agencia de noticias Mencheta, "una de las más antiguas de España", cuya organización alcanza incluso a ciudades que no son capitales de provincia. ${ }^{1}$

\footnotetext{
${ }^{1}$ La Nación. Suplemento Cincuentenario, domingo 4 de enero de 1920, p. 2.
}

En otra parte del suplemento, recuerda el primer servicio cablegráfico de Havas Reuter publicado en el diario en 1877, tan solo tres años después del tendido del cable interoceánico. Por entonces ambas empresas acordaron el envío de telegramas de Europa con "noticias de los más importantes sucesos políticos". ${ }^{2}$ Más adelante, se presenta en grandes letras la sección "Cómo se hace un diario moderno: 'La Nación'. La más grande manifestación del progreso". Una pintura campestre ilustra cómo "pintorescas diligencias" transportaban el diario medio siglo atrás. Más abajo, de mayor tamaño y en el centro de la página, se impone la fotografía de la trompa de un aeroplano apuntando al cielo, con grandes paquetes atados al fuselaje. Vale la pena reproducir la leyenda explicativa: "'La Na-

\footnotetext{
${ }^{2}$ Ibid., p. 15. El auge del cable en la prensa porteña se manifiesta en la década de 1890 . Véase Lila Caimari, "En el mundo-barrio. Circulación de noticias y expansión informativa en los diarios porteños del siglo XIX", Boletín del Instituto de Historia Argentina y Americana “Dr. Emilio Ravignani”, 33 Serie, n 49, 2018, p. 96. Véase también Martín Bergel, "Modernización de la prensa y nuevas imágenes del Oriente. Una aproximación al problema de la emergencia de una opinión pública sobre temas globales (Buenos Aires, 1880-1914)", en I. de Torres (ed.), Prensa, literatura y política en las primeras décadas del siglo $\mathrm{XX}$, Montevideo, Comisión Sectorial de Investigación Científica / Universidad de la República, 2017, pp. 195-218.
} 
ción' ha usado en el último año el aeroplano como medio de transporte a las ciudades más lejanas. Los paquetes de ejemplares colgados en el exterior de las cabinas y dentro de ellas, en un Airco, piloteado por el mayor Kingsley y tripulado por un redactor del diario, momentos antes de partir para Tucumán". ${ }^{3}$ Así, las noticias de todo el globo llegaban al diario de manera instantánea por vía telegráfica, y luego cada ejemplar arribaba con una velocidad inédita a las manos de sus lectores, idealmente, en cada rincón del país. Estas dos tecnologías de la velocidad parecían situar con todo derecho a La Nación y a la Argentina dentro de la modernidad global del momento.

No obstante, la relación entre empresa periodística y aviación, ${ }^{4}$ en la Argentina y en el mundo, tiene su origen una década atrás, durante la "Belle Époque". El período que actualmente se conoce como el de la "aviación pionera" comienza en 1908 y culmina en 1914, cuando estalla la Gran Guerra y el sport muta profundamente hacia otra experiencia. En efecto, desde la exitosa exhibición de Wilbur Wright en Le Mans en 1908, y en coincidencia, además, con el nivel técnico alcanzado por aparatos concurrentes, ese año se desata una fiebre mundial por los aeroplanos, con epicentro en Europa y los Estados Unidos. Se dispara una sucesión de exhibiciones y competencias deportivas de aeroplanos en todas partes y se baten records con frecuencia. El clímax de popularidad de ese nuevo deporte se constata al año siguiente, especialmente luego del cruce del Canal de la Mancha por Louis Blériot en julio y del éxito de la Grande Semaine d'Aviation de la Champagne de agosto, en las afueras de Reims.

\footnotetext{
${ }^{3}$ La Nación. Suplemento Cincuentenario, domingo 4 de enero de 1920, Sección VI.

${ }^{4}$ Mantenemos la distinción de época entre "aviación", referida a los vuelos motorizados de los "más pesados que el aire", y "aerostación", concerniente a globos y dirigibles.
}

La historia cultural de la aviación está centrada en las experiencias europeas y norteamericanas. Explorar desde el escenario argentino -en particular desde la ciudad de Buenos Aires y su área de expansión- ese momento global de irrupción espectacular del vuelo mecánico, de 1908 a 1910, cuando el aeroplano se consagra como símbolo por excelencia de la modernidad, y su relación con la empresa periodística de entonces, en pleno crecimiento y cada vez más orientada hacia un público de masas, nos permitirá comprender mejor la dimensión cultural y comercial de este doble proceso en clara retroalimentación. La experiencia argentina del nuevo sport se vivió primero en 1908 y 1909 desde las páginas de diarios y revistas. Habrá que esperar al inicio de 1910 para que, en homenaje al Centenario de Mayo, un grupo de entusiastas sportmen contraten pilotos europeos para que realicen exhibiciones en el país con sus propios aeroplanos. Hasta el día de hoy hay quienes atribuyen el primer vuelo en aeroplano en la Argentina al italiano Ricardo Ponzelli, quien fuera invitado por el Barón Antonio de Marchi, presidente honorario de la Sociedad Sportiva Argentina. Otros consideran que fue el francés Henri Brégi quien logró en Campo de Mayo algo más que un salto. Este piloto vino contratado por el Aero Club Argentino, donde gravitaba la figura de Jorge Newbery. El espíritu de competencia y la fiscalización de records entre los "más pesados que el aire" quedaban instalados de ese modo en suelo argentino desde las primeras exhibiciones.

Ahora bien, esta novedad importada de Europa era en gran medida una prolongación del género de las exhibiciones y las competencias ciclísticas, automovilísticas y de ascensión de globos al cual el público argentino, especialmente de las grandes ciudades, estaba cada vez más acostumbrado. No obstante, junto con estos antecedentes también ejerció influencia local en los años previos al Centenario el sistemático bombardeo de noticias de 
cable en los diarios comerciales sobre los avatares cotidianos de la aerostación y en particular de los "más pesados que el aire" en cada rincón del mundo. En efecto, existía una sociedad lectora de periódicos y revistas ilustradas que, desde por lo menos 1908, estaba deseosa de convertirse en el público de este nuevo espectáculo de masas. Si acaso exageramos sobre la masividad de ese entusiasmo, por lo menos no había dudas de que el gran público, llegado el año 1910, ya tenía noticias de las asombrosas demostraciones aéreas de esas máquinas voladoras, los eventuales accidentes esperables, la audacia de los pilotos renombrados, la progresión de records mundiales, las expectativas comerciales de los meetings del nuevo sport y las posibles reacciones de los públicos de estos espectáculos.

En este sentido, nuestro argumento es que las noticias globales -publicadas casi en sincronía gracias a los telegramas internacionales con vocación de ampliar el mercado de lectores- prepararon gradualmente una sensibilidad local sobre la que consiguió aclimatarse rápidamente la novedad importada de Europa: los vuelos en aeroplano. ${ }^{5}$ En 1908 y 1909 la prensa periódica desempeñó un papel fundamental en la instalación de un sueño de modernidad local asociado al aeroplano, y preparó un imaginario para un nuevo espectáculo deportivo que incluía tanto proyectos de desarrollo militar como oportunidades de be-

\footnotetext{
${ }^{5}$ Sobre la relación entre empresa y "poéticas" periodísticas, y la experiencia del vuelo, se destacan el dossier coordinado por Mélodie Simard-Houde, "Introduction. Pour une poétique médiatique de la 'conquête de l'air", Nacelles, dossier "La presse et la conquête de l'air. Histoires, imaginaires, poétiques", en línea 01/04/2019<http://revues.univ-tlse2.fr/pum/nacelles/ index.php?id=568>; Luc Robène y Dominique Bodin, "Le feuilleton aéronautique à la Belle Époque", Le Temps des médias, n 9, 2007/2008, pp. 47-62; y Benoît Lenoble, "L'aéroplane et le ballon vus par le journal. Technique aérienne et imaginaire médiatique en France (de 1906 au début des années 1920)", Hypothèses, 1, 9, 2006, pp. 209-220.
}

neficio comercial privado. La saturación de notas cablegráficas y artículos sobre temas de aviación entre 1908 y 1909 en la prensa comercial argentina permitió que se viviera la aviación antes de la aviación, y generó el contexto cultural necesario para que cuando esta práctica arribara en 1910, la sociedad porteña pudiera autopercibirse rápidamente en sintonía con el "mundo civilizado".

Nuestra hipótesis es que gracias a las noticias instantáneas se consolidó en los lectores de prensa entre 1908 y 1909 una conciencia y expectativa globales sobre un nuevo ícono de la modernidad y el progreso: el aeroplano. No era necesario viajar a París, Nueva York o Londres para conocer los nombres de los nuevos -y muchas veces efímeros- héroes pilotos, exitosos inventores, los avatares de esta novedosa industria y su incipiente mercado, los nuevos modelos de aeroplanos y los tipos de motores, así como los records y el desarrollo de campeonatos organizados en las ciudades europeas, norteamericanas y, no menos importante, de cualquier otra parte del mundo. El ideal de la sincronía global de la noticia que había prometido el cable -como advierte Caimari, no estrictamente diseñado según lógicas "imperiales"- y la mercancía de la "novedad" periodística daban marco y estímulo al desarrollo de la aviación en el país, en particular desde su capital y localidades cercanas. Y también ocurría en sentido inverso, la superación casi diaria de los records de estas primitivas máquinas de locomoción aérea necesitaba de un sistema de comunicación extenso en el espacio y también eficaz en la inmediatez para comunicar y medir los constantes hitos de un progreso considerado universal, aunque con ineludibles connotaciones nacionales. Hitos que en ocasiones eran superados de una semana a otra desde distintos rincones de Europa o en los Estados Unidos, aunque también desde la periferia. Un par de años después del lapso estudiado en este trabajo, el cabo Teodoro Fels obtuvo el record mundial de vuelo 
sobre el agua al unir Buenos Aires con Montevideo en un Blériot (diciembre de 1912), y Jorge Newbery batió el record mundial de altura en un monoplano Morane-Saulnier (febrero de 1914, veinte días antes de su fatal accidente en una simple demostración), aunque la proeza no fue homologada por la comisión internacional por no cumplir con el reglamento que exigía un mínimo de 150 metros de diferencia. En 1905 se había creado la Federación Aeronáutica Internacional (FAI), días después de la realización de la primera conferencia aeronáutica internacional. Su objetivo consistía en catalogar, fiscalizar y comunicar los records para uniformar criterios y hacerlos comparables, además de proteger la titularidad del responsable de la hazaña. En consecuencia, los vuelos de los primeros aeroplanos y también las experiencias de la cada vez más perfeccionada aerostación eran comentados en la prensa, que informaba los records que cotidianamente daban la medida del progreso moderno y capturaban el asombro de los lectores. ${ }^{6}$

Este artículo breve tiene como sustento empírico, en primer lugar, un trabajo cuantitativo sobre la sección de cables internacionales del periódico La Nación para dar cuenta del espacio dedicado a temas de aviación y aerostación durante 1908 y buena parte de 1909. Un segundo cuadro muestra cuántas noticias sobre inventos/experiencias de vuelo en aeroplano refieren a competencias, records y/o accidentes. Desde un enfoque cualitativo, a continuación ofrecemos algunos ejemplos de la configuración de un imaginario en torno al aeroplano en el escenario porteño, a partir de expresiones de esta moda en artículos de la revista ilustrada Caras y Caretas, especialmente en textos que

\footnotetext{
${ }^{6}$ Sobre los records y la cuantificación de las performances deportivas, véase el clásico de Allen Guttmann, From ritual to record. The Nature of Modern Sports, Nueva York, Columbia University Press, 1978; o más recientemente Jim Parry, "The idea of the record", Sport in History, vol. 26, $\mathrm{n}^{\circ}$ 2, 2006, pp. 197-214.
}

refieren a temas ajenos al campo deportivo o tecnológico. Por esta razón denominamos a sus autores "mediadores mediados". Junto con ello señalamos otros ejemplos de este nuevo imaginario en otros órdenes de la cultura. Para finalizar este recorrido, apuntamos algunas observaciones de los primeros vuelos en Buenos Aires y sus localidades aledañas en franco crecimiento en 1910 y la inscripción global de esta experiencia en el flujo de espectáculos análogos que se desarrollaban al mismo tiempo en otras partes del globo con pilotos itinerantes encendidos de fama mundial.

\section{Cuadros preliminares}

En estos dos gráficos observamos la evolución de la cantidad de noticias sobre aeronavegación en la sección "Telegramas Internacionales (de nuestros corresponsales)" del periódico La Nación, de enero 1908 a agosto de 1909.' Puede comprobarse el progresivo aumento de las noticias dedicadas a la temática y también la atención diferencial consagrada a los tres medios de locomoción aérea vigentes. Las noticias reportan sucesos aeronáuticos de Francia, Estados Unidos, Inglaterra, Alemania, Italia, Bélgica, Rusia, España, Rumania, Egipto, Australia, Canadá, Holanda, Brasil y Chile.

En el cuadro 1 se observa cómo las noticias de los vuelos en aeroplano dan un primer salto en los meses de verano del hemisferio norte en 1908 en desmedro de la aerostación, al tiempo que las noticias sobre dirigibles superan gradualmente las referidas a los globos. Sin embargo, el mayor aumento se producirá en los meses estivales del año siguiente, aunque esta vez aparece una brecha más signifi-

\footnotetext{
${ }^{7}$ Debido a restricciones impuestas por la pandemia de Covid-19, no hemos podido relevar los meses de julio y agosto de 1908, ni de septiembre a diciembre de 1909 . Afortunadamente esto no impide detectar tendencias.
} 
Cuadro 1. Noticias sobre aeronavegación en "Telegramas internacionales" en La Nación (enero 1908-agosto 1909)

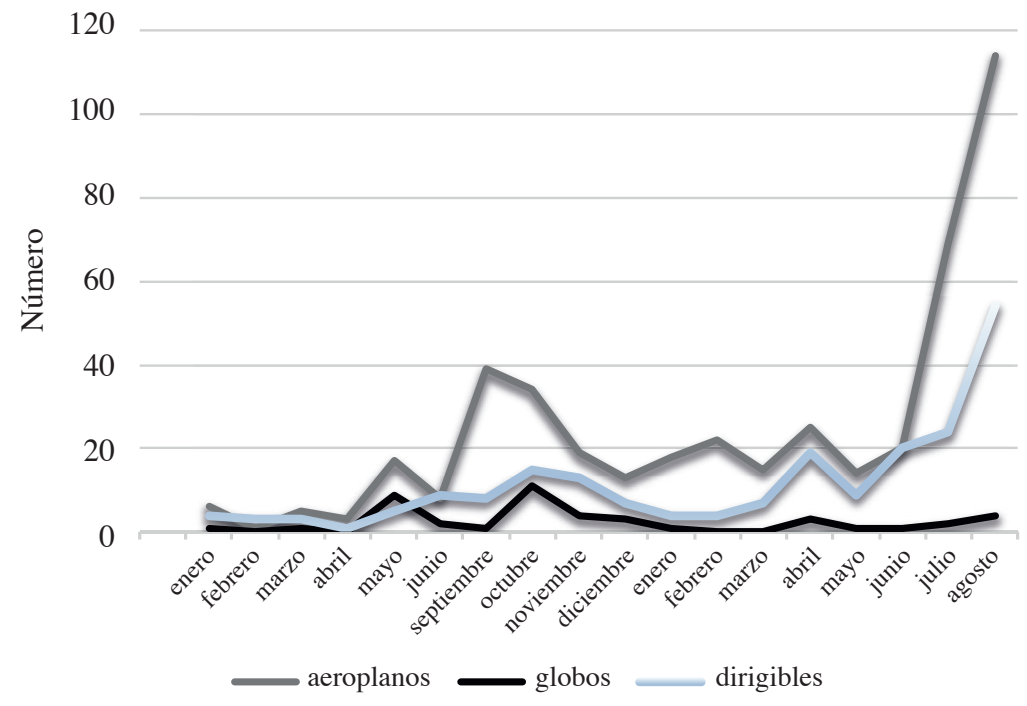

Cuadro 2. Alusiones a competencias, records y/o accidentes del total de noticias sobre inventos/experiencias de vuelo en aeroplano en "Telegramas internacionales", La Nación (enero 1908-agosto 1909)

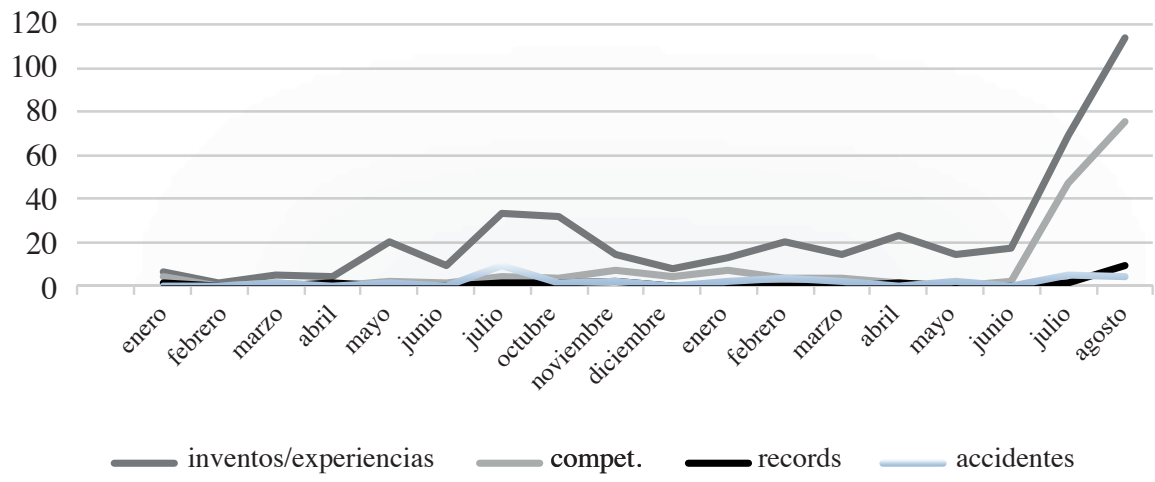

cativa en la atención dedicada a los modernos dirigibles con respecto a los globos. Este aumento vertiginoso en los cables lo dispara el cruce de Blériot, una noticia de fuerte impacto mundial, y se acrecienta debido al desarrollo de los primeros meetings, datos confirmados en el cuadro 2.

\section{"Mediadores mediados"}

Los mediadores por excelencia en el ámbito de la aeronavegación fueron Jorge Newbery, cofundador y posterior presidente del Aero Club Argentino, así como otros miembros conspicuos de aquella institución, como Aa- 
rón Anchorena, quien en 1907 le compró en París a Alberto Santos Dumont el famoso globo que rebautizó "Pampero", o Víctor Laborde, empresario automovilístico y representante en el país de la revista $L^{\prime}$ Auto, la cual patrocinó el viaje de Brégi. ${ }^{8}$ También sirvieron a la promoción del vuelo en globo en el país las ascensiones del diputado Alfredo $\mathrm{Pa}$ lacios, amigo de Newbery, especialmente luego de la parálisis creada en la actividad luego de la tragedia de su hermano Eduardo y el sargento Eduardo Romero.

No obstante, hay otras figuras intelectuales que intervienen en el periodismo de ese momento, en cuya producción se observa la influencia de la nueva cultura del aeroplano por las imágenes que utilizan, aun tratándose de relatos referidos a otros temas. En una extensa nota de 1909 sobre el pensamiento católico de Rómulo Murri y su relación con el Vaticano, Juan José de Soiza Reilly desliza: "Un Cristo de nuestros tiempos andaría con pantalones, con sombrero y con lentes. Para la Resurrección, en vez de nubes, tendría un aeroplano [...]". ${ }^{9}$ En su relato "Un idilio", Horacio Quiroga escribe: "Apresuró el paso, esforzándose en pensar en otra cosa, en cualquiera, en una puerta de su casa, que chirriaba; en los aeroplanos de Curtiss [...]". ${ }^{10}$ En más de una ocasión, el humor gráfico de José María Cao ironiza sobre la moda del aeroplano y a la vez lo emplea para satirizar la realidad política y social del momento. Por su parte, Enrique Gómez Carrillo, corresponsal en París de La Nación -y de muchos otros periódicos-, da cuenta de la invasión de la temá-

\footnotetext{
${ }^{8}$ Eloy Martin, "La aviación en el hipódromo de Longchamps", s/r, 2014, p. 8. En línea: <https://www.histarmar.com.ar/AVIACION/EloyMartin/La\%20aviacion\%20 en $\% 20$ el\%20hipodromo\%20de\%20Longchamps.pdf>.

${ }^{9}$ Juan José de Soiza Reilly, "El modernismo católico. Lo que dice don Rómulo Murri”, Caras y Caretas, n 571 , 11 de septiembre de 1909.

${ }^{10}$ Horacio Quiroga, "Un idilio", Caras y Caretas, ${ }^{\circ}$ 584, 11 de diciembre de 1909 .
}

tica aérea en la literatura francesa de 1910: "tal vez el año próximo volverá el gusto por la historia, aunque según mis cálculos el porvenir pertenece a la navegación aérea". ${ }^{11}$

La cultura del "aeroplano antes del aeroplano" emerge ubicua por su carácter global y también por su pregnancia en múltiples órdenes de la vida social, vehiculizada por la prensa periódica. En la revista Caras y Caretas de noviembre de 1909 se publica un croquis con indicaciones para armar, con bambú y tela, aeroplanos modelos Wright y Farman, sin dejar de señalar los pasos para fabricar también la libélula Bléirot. En esos días, durante la ascensión del globo "Huracán" en el Hipódromo de la Sociedad Sportiva a beneficio de la Asociación Damas de Misericordia, se organizó conjuntamente una carrera con esos modelos de aeroplanos. ${ }^{12}$ En general, en las páginas de diarios y revistas ilustradas se reiteran las publicidades de productos de diversa índole que utilizan la imagen del aeroplano, prestigioso símbolo de modernidad y superación de límites. ${ }^{13}$ Se venden aeroplanos de juguete para niños y niñas, y la tienda Gath y Chaves presenta un sombrero para damas estilo "aeroplano". ${ }^{14}$ En las familias de la élite porteña muchos jóvenes no solo se asocian al Aero Club antes de la llegada de los aparatos, sino que empiezan a elucubrar iniciativas empresariales vinculadas a la aviación, aunque a veces sin suerte. ${ }^{15}$

\footnotetext{
${ }^{11}$ La Nación, 13 de enero de 1910, p. 7.

${ }^{12}$ Caras y Caretas, 20 de noviembre de 1909, n 581 .

${ }^{13}$ El intenso carácter global de este nuevo imaginario, incluso previo a las primeras experiencias en aeroplano, también se verifica en la prensa de muchos otros países de la región.

${ }^{14}$ Caras y Caretas, 23 de octubre de 1909.

${ }^{15}$ El joven Julio Senillosa intentó en 1909 contactarse con los hermanos Wright para ser su representante en Buenos Aires. La fiebre de la aviación también se traducía como empresa prometedora para una familia en decadencia, Roy Hora y Leandro Losada, Una familia de la elite argentina: Los Senillosa (1810-1930), Buenos Aires, Prometeo, 2016, p. 129.
} 
Por último, en el liminal mes de enero de 1910, un aficionado en Tigre había emprendido en solitario la construcción de un aeroplano. ${ }^{16}$ Con la experiencia de los primeros vuelos en Buenos Aires desde febrero de ese año, esta pregnancia cultural del objeto aeroplano, como es de esperar, se intensificó considerablemente. Por ejemplo, en las listas de carreras del hipódromo aparece un caballo bautizado "Aeroplane"; y en la sección policiales nos enteramos de que en abril hubo "una 'razzia' de malevos" en el café "Aeroplano". ${ }^{17}$ Para la Navidad de 1910, los niños ya no se conforman con simples juguetes de aeroplanos, "los quieren que funcionen como los de verdad". ${ }^{18}$

\section{0: del acontecimiento de la noticia a la noticia del acontecimiento}

Este recorrido concluye con algunas reflexiones sobre las primeras experiencias de vuelos en aeroplano en la Argentina en 1910, específicamente en Buenos Aires, con sus localidades cercanas en plena expansión, la ciudad bonaerense de Mar del Plata -conectada desde sus orígenes con la sociedad porteña- y finalmente el anuncio del desafío Buenos Aires-Rosario. Son numerosos los estudios que relatan con detalle el mito fundacional de la aeronáutica en el país. Destacamos los trabajos recientes con documentación detallada de Eloy Martín ${ }^{19}$ y la elocuente biografía de Jorge Newbery de Alejandro Guerrero, aunque el registro de divulgación de

\footnotetext{
16 "La aviación en Argentina. Un aeroplano argentino", La Nación, 11 de enero de 1910, p. 9.

${ }^{17}$ Respectivamente, Caras y Caretas, $\mathrm{n}^{\circ}$ 613, 2 de julio de 1910; La Nación, 14 de abril de 1910, p. 11.

18 "Un viaje al país de los juguetes", Caras y Caretas, $\mathrm{n}^{\circ}$ 638, 24 de diciembre de 1910. En los años sucesivos el aeroplano también empezará a inspirar algunas letras de tangos.

${ }^{19}$ Eloy Martín, Los vuelos del Centenario. Crónica de la aviación argentina en 1910, Buenos Aires, s/r, 2009.
}

esta última impide corroborar algunos de sus pasajes. ${ }^{20}$ En este último apartado nos interesa caracterizar el modo en que esta experiencia local se inscribe en una tendencia global con dinámicas similares, si no idénticas en muchos aspectos.

Diversas ciudades utilizaron los meetings de aviación para fomentar el turismo local. Luc Robène et. al. demuestran, en este sentido, la estrategia de la municipalidad de Pau para atraer a los hermanos Wright para realizar sus demostraciones e inaugurar una escuela de aviación. De ese modo la localidad pretendía recapturar un público aristocrático y burgués que desde hacía un tiempo pasaba sus veranos exclusivamente en Biarritz. ${ }^{21} \mathrm{El}$ contrato del piloto francés Brégi en Buenos Aires incluía exhibiciones en el hipódromo de Mar del Plata, polo turístico bonaerense de relieve social. En efecto, al poco tiempo de llegar a Buenos Aires, Brégi partió para la ciudad balnearia en plena temporada de febrero de 1910. En el primer caso, el propósito consistía en recuperar turistas, mientras que en el segundo se trataba de aprovechar a los que estaban allí para estimular el interés por la nueva práctica. Por lo demás, vale recordar que el famoso meeting de Reims había sido financiado por los productores de champagne para promocionar su terroir.

También se observan en sincronía usos semejantes de las exhibiciones aéreas en la periferia por parte del comercio inmobiliario. Los diarios porteños no ahorraron tinta en informar en 1910 sobre el éxito de "The Great Week of Aviation at Heliopolis" (Heliopolis era un nuevo suburbio en las afueras de El

\footnotetext{
${ }^{20}$ Alejandro Guerrero, Jorge Newbery, Buenos Aires, Emecé, 1999.

${ }^{21}$ Luc Robène, Dominique Bodin y Stéphane Héas, "Pau et l'invention de l'aviation 'sportive' (1908-1910). Des enjeux technologiques aux plaisirs mondains: naissance d'un loisir et nouveaux pouvoirs du corps", Staps, $\mathrm{n}^{\circ} 87$, 2010/11, pp. 13-31.
} 
Cairo). En 1909, luego del exitoso evento de Reims, un grupo de empresarios coloniales de Egipto había contactado a varios pilotos del momento para que a comienzos del año siguiente participasen de un concurso de aviación con importantes premios. Construyeron un aeródromo inmenso con diferentes servicios (Caras y Caretas reproducía una fotografía al respecto). ${ }^{22} \mathrm{Su}$ intención era atraer la mirada del mundo entero a su proyecto inmobiliario de hotelería de lujo en esa zona. ${ }^{23} \mathrm{Se}-$ gún Eloy Martin, la empresa Ricardo J. Davel y Cía intercedió para que Brégi realizara vuelos los días de subastas de lotes en Longchamps y así atrajera más compradores. ${ }^{24} \mathrm{La}$ publicidad gráfica de los remates en la prensa porteña incluía el dibujo del aeroplano, del mismo modo que los empresarios en Egipto lo habían utilizado en cientos de postales publicitarias que enseñaban los futuros edificios. Tanto en El Cairo como en Buenos Aires las entradas para estos espectáculos se podían comprar en determinados hoteles céntricos.

Como vemos, desde el comienzo este modelo de espectáculo no solo tenía lugar en las afueras de las grandes capitales europeas y norteamericanas, sino especialmente en ciudades medianas y pequeñas pero con decidida aspiración de notoriedad, como Le Mans, Reims, Brescia, Pau, Verona, Palermo, Ostende, Douai, Vichy, Doncaster, Blackpool, Antwerp, etc. Y en los casos de Heliopolis, Longchamps y Villa Lugano, estas zonas doblemente alejadas (periferias de la periferia) consiguieron mediante estas exhibiciones ubicarse momentáneamente en el "centro" de la atención.

${ }^{22}$ Caras y Caretas, n 599, 26 de marzo de 1910.

${ }^{23}$ Gary Leiser, "The First Flight Above Egypt: The Great Week of Aviation at Heliopolis, 1910", Journal of the Royal Asiatic Society, Third Series, vol. 20, n 3, 2010, pp. 267-294.

${ }_{24}$ Martin, "La aviación en el hipódromo de Longchamps", pp. 2 y 17.
El desplazamiento del público hacia los "campos de volación" se realizaba en ferrocarril, a veces con frecuencias especiales, porque los sitios se encontraban por lo general en las afueras de las ciudades. Muchos espectadores, y no solo periodistas, dejaron su testimonio sobre esas excursiones. Le Corbusier, por ejemplo, recuerda no solo el entusiasmo por los vuelos del año 1909, sino que también alude a la ira popular generada por problemas de organización en el trayecto de París a PortAviation en Juvisy $(23 \mathrm{kms}) .{ }^{25}$ Franz Kafka narra ese mismo año para el periódico Bohemia los imponderables que experimentó para llegar al "campo di volo", en el sureste de Brescia, con el fin de apreciar el circuito aéreo de septiembre.

Aunque su composición social variaba, los públicos reaccionaban de manera similar en cualquier parte del mundo: las frustraciones por la espera y la anulación de vuelos -la mayoría de las veces debido al mal tiempo-podía desencadenar el destrozo de instalaciones. Los aterrizajes eran peligrosos, porque el público exultante podía invadir el terreno; e incluso en tierra, en determinadas ocasiones la euforia de la gente podía dañar al piloto y al aparato.

Desde fines del siglo XIX, la prensa de vocación masiva no solo informaba sobre los sensacionales encuentros deportivos, sino que comenzó a organizar ella misma competencias de ciclismo, automovilismo, aerostación y luego aviación. Por ejemplo, Le Figaro organizó un concurso aerostático en 1905, y The Daily Telegraph impuso el propio en $1908 .{ }^{26}$ Este mismo año, el periódico Daily Mail ofreció unas 1.000 
libras esterlinas a quien cruzara en aeroplano el Canal de la Mancha, hazaña lograda por Blériot en julio de 1909. Al mes siguiente, el avión fue comprado por el periódico francés $L e M a$ tin para exhibirlo en su local. En 1909 se creó la Copa de aviación "Gordon Bennett", instituida por el magnate de la prensa. Al año siguiente, mediante anuncios rimbombantes $L e$ Matin ofreció 100.000 francos al aviador que uniera París-Troyes-Nancy-Mézieres-DouaiAmiens-París. Nuevamente el Daily Mail estableció en abril de 1910 un premio de 10.000 libras esterlinas al aviador que volara de Londres a Manchester. En 1911, Le Petit Journal organizó la carrera París-Turín-Roma, luego de que Le Petit Parisien impulsara el raid ParísMadrid. Este mismo año, Le Journal se asoció en agosto con otros diarios europeos para organizar "Le Circuit d'Europe", con la intención de celebrar la paz fraternal uniendo las ciudades de París, Bruselas, Utrecht, Londres y Berlín, entre otras. Mientras tanto, el periódico $L a$ Dépêche ofreció un premio para el piloto que uniera en un solo tramo Pau-Toulouse.

En la Argentina, La Nación no se quedó atrás en esta estrategia publicitaria. Además de los premios de aerostación y aviación ofrecidos por el Aero Club Argentino, el empresario Carlos Torquinst y la tabacalera de Juan Carter -la cual donó la copa para una carrera de globos en 1909-, La Nación organizó el 17 de noviembre de 1910 un raid de aeroplanos que se concretó al año siguiente. Destinó un premio de 15.000 francos para la travesía Rosario-Buenos Aires. ${ }^{27}$ De este modo, la prensa local contribuyó a la invención de la aviación en la Argentina saturando a los lectores con noticias sobre el nuevo sport entre 1908 y 1909, y después de 1910 organizando uno de estos lucrativos espectáculos de acuerdo a la tendencia global.

${ }^{27}$ La Nación, 22 de mayo de 1911, citado en Guerrero, Jorge Newbery, p. 271; también en Martín, Los Vuelos del Centenario, p. 13.
En conclusión, el asombro, la cultura y la economía de los primeros espectáculos del nuevo sport entre 1908 y 1910 hicieron eclosión al mismo tiempo en muchas regiones del globo, aun antes de la presencia de los aparatos, como pudimos comprobar en las páginas de La Nación y Caras y Caretas. Buenos Aires se sumó a la competencia global por los records de las nuevas máquinas a partir de 1910, gracias a la circulación mundial de pilotos europeos y norteamericanos, las nuevas estrellas del momento. El espectáculo y el despegue globales de la industria aeronáutica son en gran medida deudores de las ambiciones de la prensa comercial y de los adelantos en las tecnologías de la comunicación.

\section{Bibliografía citada}

Bergel, Martín, "Modernización de la prensa y nuevas imágenes del Oriente. Una aproximación al problema de la emergencia de una opinión pública sobre temas globales (Buenos Aires, 1880-1914)", en I. de Torres (ed.), Prensa, literatura y política en las primeras décadas del siglo XX, Montevideo, Comisión Sectorial de Investigación Científica / Universidad de la República, 2017, pp. 195-218.

Caimari, Lila, "En el mundo-barrio. Circulación de noticias y expansión informativa en los diarios porteños del siglo XIX", Boletín del Instituto de Historia Argentina y Americana "Dr. Emilio Ravignani", $3^{\mathrm{a}}$ serie, $\mathrm{n}^{\circ} 49$, 2018, pp. 81-116.

Guerrero, Alejandro, Jorge Newbery, Buenos Aires, Emecé, 1999.

Guttmann, Allen, From ritual to record. The Nature of Modern Sports, Nueva York, Columbia University Press, 1978.

Hora, Roy y Leandro Losada, Una familia de la elite argentina: Los Senillosa (1810-1930), Buenos Aires, Prometeo, 2016.

Leiser, Gary, "The First Flight Above Egypt: The Great Week of Aviation at Heliopolis, 1910", Journal of the Royal Asiatic Society, Third Series, vol. 20, n 3, 2010, pp. 267-294.

Lenoble, Benoît, "L'aéroplane et le ballon vus par le journal. Technique aérienne et imaginaire médiatique en France (de 1906 au début des années 1920)", Hypothèses, 1, 9, 2006, pp. 209-220. 
Martín, Eloy, Los vuelos del Centenario. Crónica de la aviación argentina en 1910, Buenos Aires, s/r, 2009.

"La aviación en el hipódromo de Longchamps", s/r, 2014, p. 8. En línea: <https://www.histarmar.com. ar/AVIACION/EloyMartin/La\%20aviacion\%20en\%20 el\%20hipodromo\%20de\%20Longchamps.pdf $>$.

Parry, Jim, "The idea of the record", Sport in History, vol. 26, n² 2, 2006, pp. 197-214.

Quiroga, Horacio, "Un idilio", Caras y Caretas, n 584, 11 de diciembre de 1909.

Robène, Luc y Dominique Bodin, "Le feuilleton aéronautique à la Belle Époque", Le Temps des médias, $\mathrm{n}^{\circ} 9$, 2007/8, pp. 47-62.

Robène, Luc, Dominique Bodin y Stéphane Héas, "Pau et l'invention de l'aviation 'sportive' (1908-1910). Des enjeux technologiques aux plaisirs mondains: naissance

\section{Resumen/Abstract}

\section{La aviación en Buenos Aires y el fenómeno noticioso global (1908-1910)}

Se argumenta que los grandes diarios y las revistas ilustradas, en busca de lectores, alimentaron en Buenos Aires un imaginario en torno a los novedosos vuelos en aeroplano antes de su llegada al país, durante 1908 y 1909; a partir de 1910, estos mismos diarios y revistas intensificaron la promoción de este deporte como estrategia publicitaria en sincronía con una experiencia global. Para ello se efectúa un análisis cuantitativo sobre la sección de telegramas internacionales del periódico La Nación. En segundo lugar, desde un enfoque cualitativo, se ofrecen ejemplos de la configuración de este imaginario en torno al aeroplano en el escenario bonaerense en $\mathrm{La}$ Nación y en Caras y Caretas. Finalmente, se inscriben los primeros vuelos en el país desde 1910 en el flujo de espectáculos que se desarrollaban al mismo tiempo y con características similares en otras partes del globo mediante la contratación de pilotos celebrados como estrellas deportivas mundiales.

\section{Palabras clave:}

Aeroplano - Prensa - Imaginario global - Buenos Aires 1908-1910

DOI: https://doi.org/10.48160/18520499prismas25.1219 d'un loisir et nouveaux pouvoirs du corps", Staps, 87, 2010/11, pp. 13-31.

Simard-Houde, Mélodie, “Porter le journal jusqu'aux nues: la presse et l'ascension en ballon homonyme à la fin du XIX ${ }^{\mathrm{e}}$ siècle", Mémoires du livre / Studies in Book Culture, 10, 1, 2018, pp. 1-44.

—, "Introduction. Pour une poétique médiatique de la 'conquête de l'air'", Nacelles, dossier "La presse et la conquête de l'air. Histoires, imaginaires, poétiques", en línea: 01/04/2019, <http://revues.univ-tlse2.fr/pum/ nacelles/index.php?id=568>.

Soiza Reilly, Juan José, "El modernismo católico. Lo que dice don Rómulo Murri”, Caras y Caretas, n 571, 11 de septiembre de 1909.

Wohl, Robert, A passion for wings. Aviation and the western imagination, 1908-1918, New Haven y Londres, Yale University Press, 1994.

\section{Aviation in Buenos Aires and the global news experience (1908-1910)}

The paper argues that major newspapers and illustrated magazines, in search of readers, fed in Buenos Aires an imaginary and an expectation around the novel airplane flights even before their arrival, during 1908 and 1909; and that later used them as an advertising strategy in synchrony with a global experience. For this purpose, it presents a quantitative analysis of the international telegram section of the newspaper La Nación. Secondly, adopting a qualitative approach, it analyzes the configuration of the imaginary around the airplane in the public sphere of Buenos Aires as it appears in $L a$ Nación and Caras y Caretas. Finally, it analyzes the early flights in the country since 1910, as part of a larger flow of shows that were taking place at the same time, and with similar characteristics, in other parts of the globe, in which pilots were hired and celebrated as world sport stars.

\section{Keywords:}

Airplane - Press - Global imaginary - Buenos Aires 1908-1910 